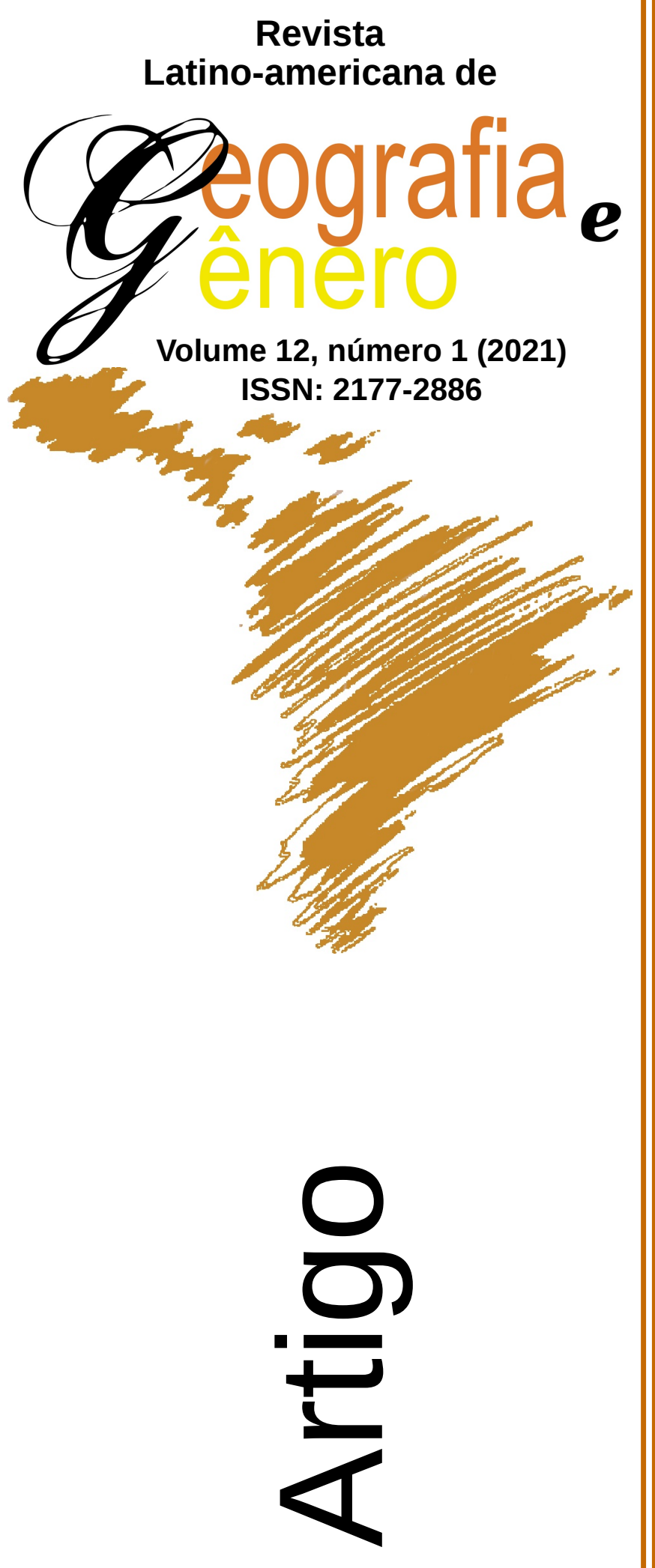

\title{
A Prostituição e a Imagem da Cidade de Amsterdã
}
La Prostitución y la Imagen de la Ciudad en Amsterdam

Prostitution and the City's Image of Amsterdam

\section{João Soares Pena}

Ministério Público do Estado da Bahia - Brasil joaopena.88@gmail.com

Como citar este artigo:

PENA, João Soares. A Prostituição e a Imagem da Cidade de Amsterdã. Revista Latino Americana de Geografia e Gênero, v. 12, n. 1, p. 97-128, 2021. ISSN 2177-2886.

Disponível em:

http://www.revistas2.uepg.br/index.php/rlagg 


\title{
A Prostituição e a Imagem da Cidade de Amsterdã
}

\author{
La Prostitución y la Imagen de la Ciudad en Amsterdam
}

\section{Prostitution and the City's Image of Amsterdam}

\section{Resumo}

Neste artigo faço uma análise do papel da prostituição para a imagem da cidade de Amsterdã a partir de dados coletados durante uma pesquisa de campo realizada na cidade. A presença da prostituição na cidade, sobretudo com o florescimento da indústria do sexo nos anos 1970, foi fundamental para forjar a imagem de Amsterdã no âmbito do mercado de turismo internacional como cidade liberal e progressista, atraindo turistas interessados no Red Light District não apenas pelo serviço sexual, mas também para o consumo da imagem associada a ele. Então, saliento as contradições que envolvem a prostituição em Amsterdã a partir da perspectiva do urbanismo para demonstrar que as ações recentes visam mudar a imagem da cidade. Por fim, mostro que a prostituição é um campo de batalha constante, pois há interesses políticos e econômicos diversos em relação a esse bairro.

Palavras-Chave: Prostituição; Amsterdã; Red Light District; Imagem da Cidade; Urbanismo.

\section{Resumen}

Este artículo analiza el papel de la prostitución en la imagen de la ciudad de Amsterdam. La presencia de la prostitución en la ciudad, especialmente con el florecimiento de la industria del sexo en la década de 1970, fue fundamental para forjar la imagen de Ámsterdam dentro del mercado turístico internacional como una ciudad liberal y progresista, atrayendo turistas interesados por el Red Light District (Barrio Rojo), no solamente por su servicio sexual sino también por el consumo de la imagen asociada a él. A continuación, destacamos las contradicciones que rodean la prostitución en Ámsterdam desde la perspectiva del urbanismo para demostrar que las acciones recientes apuntan a un cambio de imagen de la ciudad. Finalmente, se evidencia que la prostitución es un campo de batalla constante, ya que existen diferentes intereses políticos y económicos en este barrio holandés.

Palabras-Clave: Prostitución; Amsterdam; Red Light District; Imagen de la ciudad; Urbanismo.

Abstract
In this paper I analyse the role of prostitution in creating the image of the city of Amsterdam. The presence of prostitution in the city, mainly since its flourishing in the 1970s as a sex industry, was fundamental to create the image of Amsterdam as a liberal and progressive city in the international tourism market. This specific industry helped to attract tourists interested in the Red Light District not only because of the sex work but also for the consumption of the image that was attached to it. Then I highlight the contradictions involving prostitution in Amsterdam from the perspective of urbanism to demonstrate that recent actions aim at changing the city's image. In conclusion, I show that prostitution is a constant battleground as there is a plethora of political and economic interests regarding this neighbourhood.

Keywords: Prostitution; Amsterdam; Red Light District; City's Image; Urbanism. 


\section{Introdução}

Todos os dias o centro de Amsterdã se enche de turistas vindos dos mais diversos países para conhecer os atrativos da cidade. É nessa área que está um dos mais emblemáticos cartões postais não só da cidade, mas da Holanda: o Red Light District, uma das mais famosas áreas de prostituição do mundo. A história da prostituição nessa área remonta ao período medieval, quando a cidade ainda era murada. $\mathrm{O}$ fato de ser uma cidade portuária também foi um elemento que favoreceu essa atividade, uma vez que a cidade recebia viajantes que encontravam nos bordéis uma forma de diversão. Ao longo dos séculos tanto as políticas quanto a geografia da prostituição sofreram mudanças em virtude dos valores e interesses em voga em cada época (PENA, 2019a; OUTSHOORN, 2012).

Apesar da importância que a prostituição desempenhou para a dinâmica da cidade, o funcionamento de bordéis foi proibido em 1911, porém eles não desapareceram. Sua permanência no tecido urbano ao longo o século XX foi caracterizada por uma "tolerância regulada", ou seja, embora proibidos, as autoridades deixavam que funcionassem em áreas específicas da cidade. Com relação às políticas de prostituição, foi emblemática a regulamentação da prostituição e da legalização dos bordéis em 2000. Além de ter alterado a dinâmica do Red Light District, isto também reforçou a ideia de que a Holanda é um país tolerante e progressista, sendo Amsterdã a maior expoente disso (PENA, 2020; HEKMA, 2005). Se nos anos 1990 ocorreram debates que culminaram na regulamentação da prostituição em 2000, poucos anos mais tarde essa questão voltou a ser debatida. Entretando, desta vez a prostituição passou a ser considerada um elemento negativo e relacionada à criminalidade, portanto um problema a ser resolvido.

Este artigo apresenta parte dos resultados de uma pesquisa de campo realizada em Amsterdã entre 2017 e 2018 (PENA, 2020), contando com observação in loco, realização de entrevistas semiestruturadas, análise de documentos oficiais e leitura de bibliografia especializada. Aqui neste artigo busco discutir o papel da prostituição e do Red Light District para a imagem de Amsterdã e como a cidade passou a encará-los, sobretudo a partir da proposição do Plano 1012, em 2007, com intervenções urbanas realizadas no bairro. Nesse sentido, a análise do plano mostra que a intenção não era apenas combater a criminalidade que foi relacionada à prostituição, mas melhorar a imagem da cidade frente ao mercado internacional de turismo. Mas isto não foi suficiente para reposicionar a cidade nesse mercado, motivo pelo qual a Prefeitura tem mobilizado o marketing urbano para redefinir a imagem da cidade.

\section{Prostituição e Imagem da Cidade}

De Wallen é provavelmente o mais emblemático bairro de Amsterdã. Para além de sua arquitetura que remonta ao medievo, dos canais navegáveis onde turistas fazem passeios de barco, o bairro abriga um dos principais atrativos da cidade: o Red Light District. Aí, misturam-se turistas, moradores antigos, jovens estudantes moradores, trabalhadoras sexuais, crianças, policiais fazendo ronda, passantes de bicicleta e de carro etc. As ruas estreitas do bairro são, 
então, compartilhadas pelas mais diversas pessoas com os mais variados idiomas, porém não necessariamente de forma harmoniosa. Se a presença da prostituição e das drogas confere à área uma característica singular, ao longo dos anos essa coexistência tem gerado conflitos entre aqueles que nutrem interesse pela área.

A trajetória da prostituição na cidade é marcada por mudanças, conflitos e também pela tolerância à sua permanência. Como cidade portuária, Amsterdã recebia muitos viajantes, marinheiros que permaneciam na cidade por algum tempo, encontrando nos bordéis uma forma de distração. Contudo, apesar da importância da prostituição para a dinâmica da cidade, ela nunca foi socialmente aceita, mas tolerada ao longo dos séculos. Em 1911 o funcionamento de bordéis foi proibido, mas eles continuaram em atividade sob uma "tolerância regulada". Foi durante o século XX que uma indústria do sexo mais diversificada floresceu em Amsterdã, concentrando no centro da cidade diversos sexshops, clubes, teatros de sexo ao vivo, cinemas pornôs, bares, além das características vitrines (Figura 1). Isso aconteceu a partir do final dos anos 1960 e começo dos anos 1970, quando Amsterdã também vivia uma efervescência política e cultural (PENA 2019a; 2020).

Figura 1: Vitrines no Red Light District

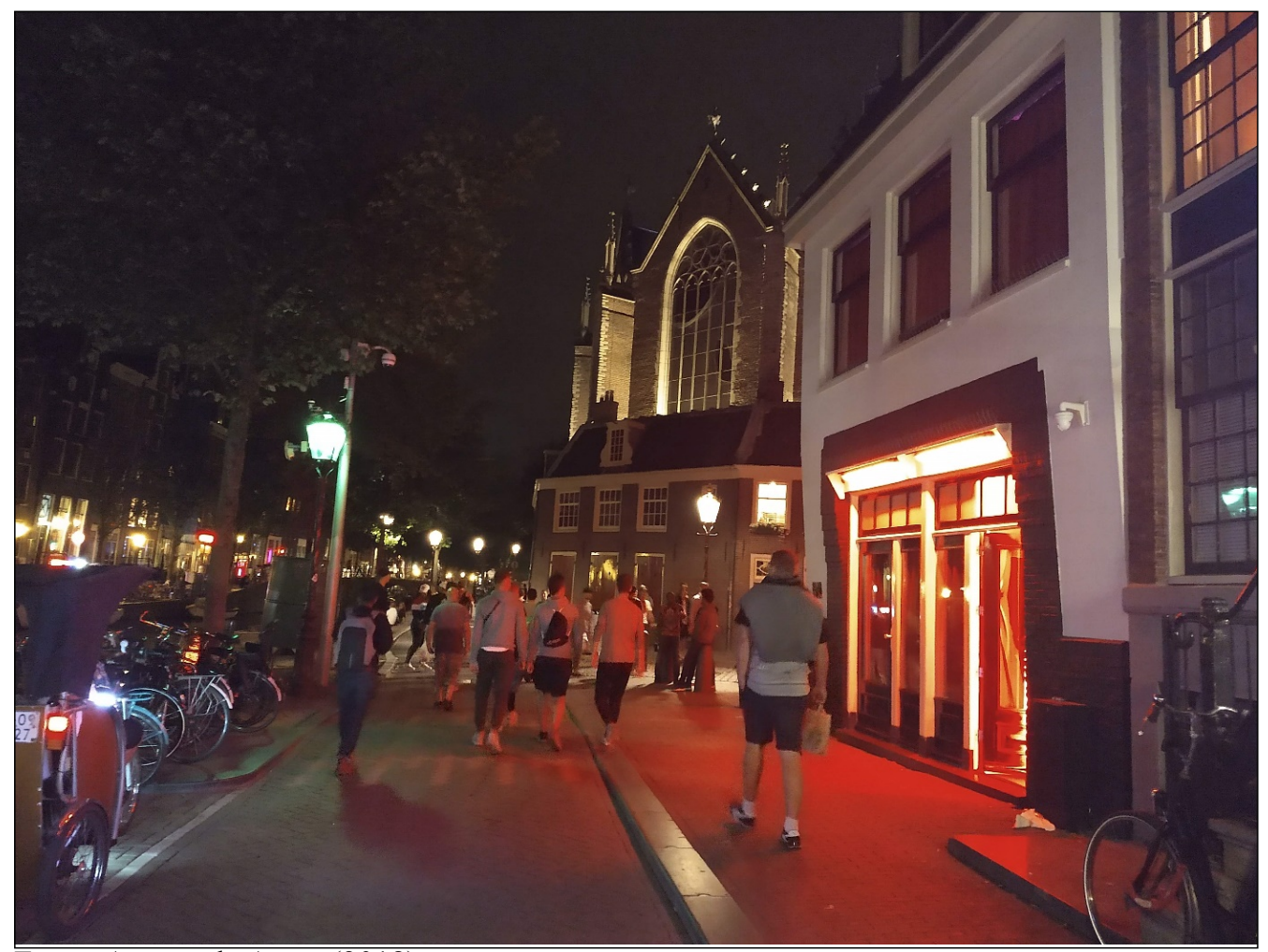

Fonte: Acervo do Autor (2018).

A existência da prostituição e outros estabelecimentos voltados ao sexo tornou o Red Light District um dos principais cartões postais de Amsterdã, atraindo turistas do mundo inteiro. Desse modo, muitos turistas visitam a área a fim de conhecer uma das mais famosas zonas de prostituição do mundo, beber cerveja, fumar maconha, se divertir. O trabalho sexual está marcado na paisagem da cidade não apenas pela presença das prostitutas nas vitrines, mas 


\section{A Prostituição e a Imagem da Cidade de Amsterdã}

também pelos mais diversos objetos sexuais e imagens nos muros do bairro (Figura 2). Em suas vitrines, as sexshops exibem sem pudores uma infinidade de objetos sexuais, instigando a curiosidade e o interesse dos passantes antes mesmo de entrarem nas lojas.

Figura 2: Imagens eróticas no Red Light District

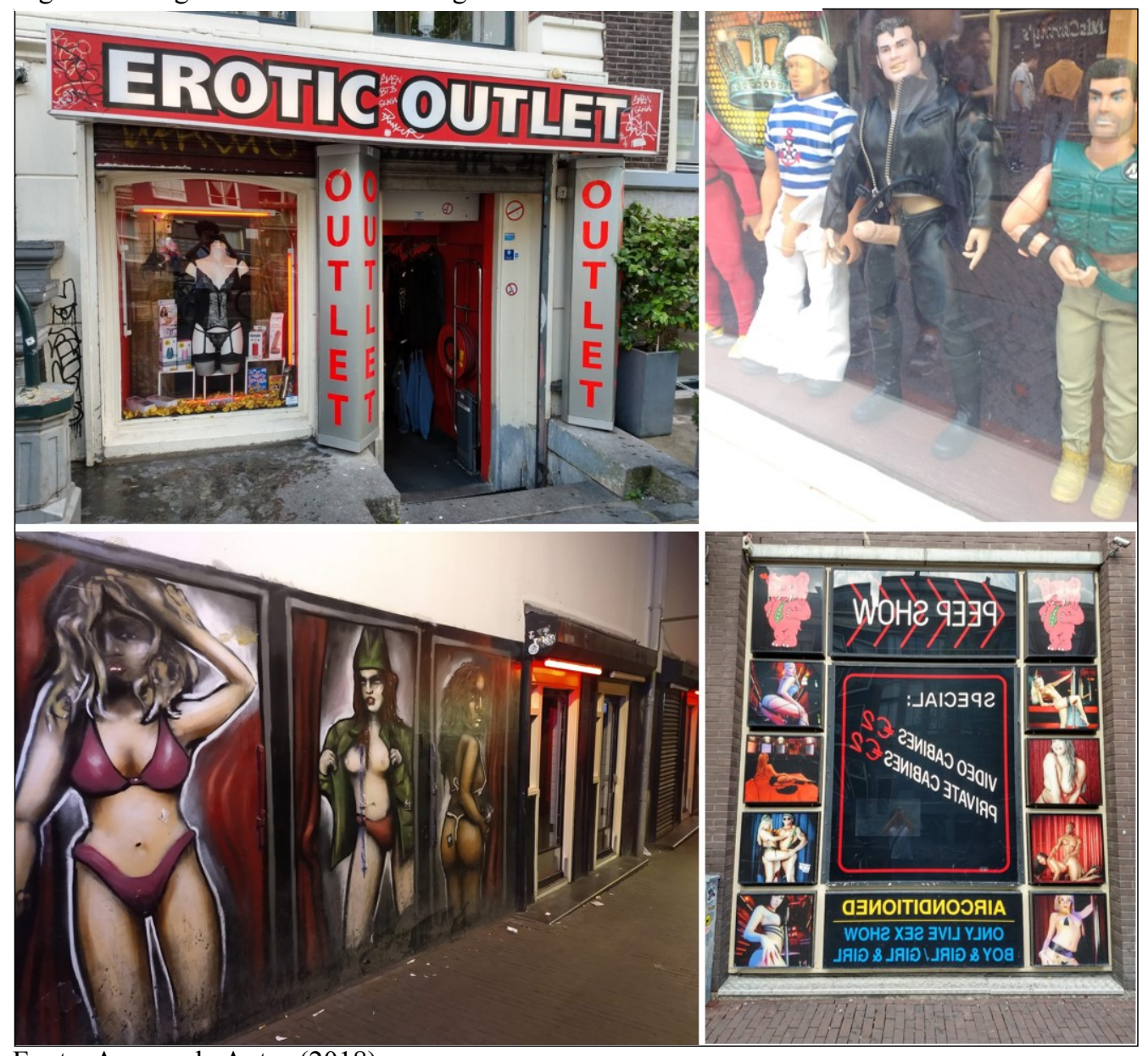

Fonte: Acervo do Autor (2018).

A importância da prostituição e do Red Light District para a cidade e para o turismo também se revela nos souvenirs que são vendidos nas inúmeras lojas do ramo espalhadas pelo bairro. Os artigos são os mais variados, dando, ao turista a possibilidade de levar uma lembrança dos elementos mais marcantes da cidade. Nos cartões postais e nos bibelôs à venda nessas lojas, a prostituição e o sexo figuram entre bicicletas, moinhos, pinturas de artistas holandeses, tulipas, entre outros (Figura 3). Desse modo, a imagem da cidade de Amsterdã está diretamente ligada à prostituição e à ideia de que esta é uma cidade liberal e progressista (PENA, 2020).

Esses souvenirs tentam sintetizar Amsterdã, capital e maior cidade do país, que acaba sendo vista como símbolo máximo de liberdade e progressismo, onde questões como prostituição e comercialização de drogas são facilmente observadas na conformação do espaço e na dinâmica urbana. Nesse sentido, Jan Nijman (1999) explica que a noção de tolerância capturada pelo turismo internacional difere-se daquela que estava relacionada à diversidade de sua população. Atualmente a ideia de tolerância atribuída a Amsterdã está 
A Prostituição e a Imagem da Cidade de Amsterdã

primeiramente associada à forma como a cidade lida com as drogas e a prostituição. $\mathrm{O}$ autor destaca que é esta última que corresponde às expectativas dos turistas que visitam a cidade com o interesse de fazer e ver coisas que não são permitidas em muitos outros lugares. É essa imagem que circula nos diversos meios de comunicação, mas também transmitidas pelos próprios visitantes, pois "[...] são as próprias pessoas (não os computadores ou a televisão) que servem como meios de informação, como transmissores globais das imagens das localidades" (NIJMAN 1999, p. 149, tradução livre). Isto é relevante, sobretudo, se considerarmos as possibilidades de compartilhamento em tempo real, proporcionado pelas redes sociais e novas tecnologias de informação.

Figura 3: Souvenirs vendidos em Amsterdã

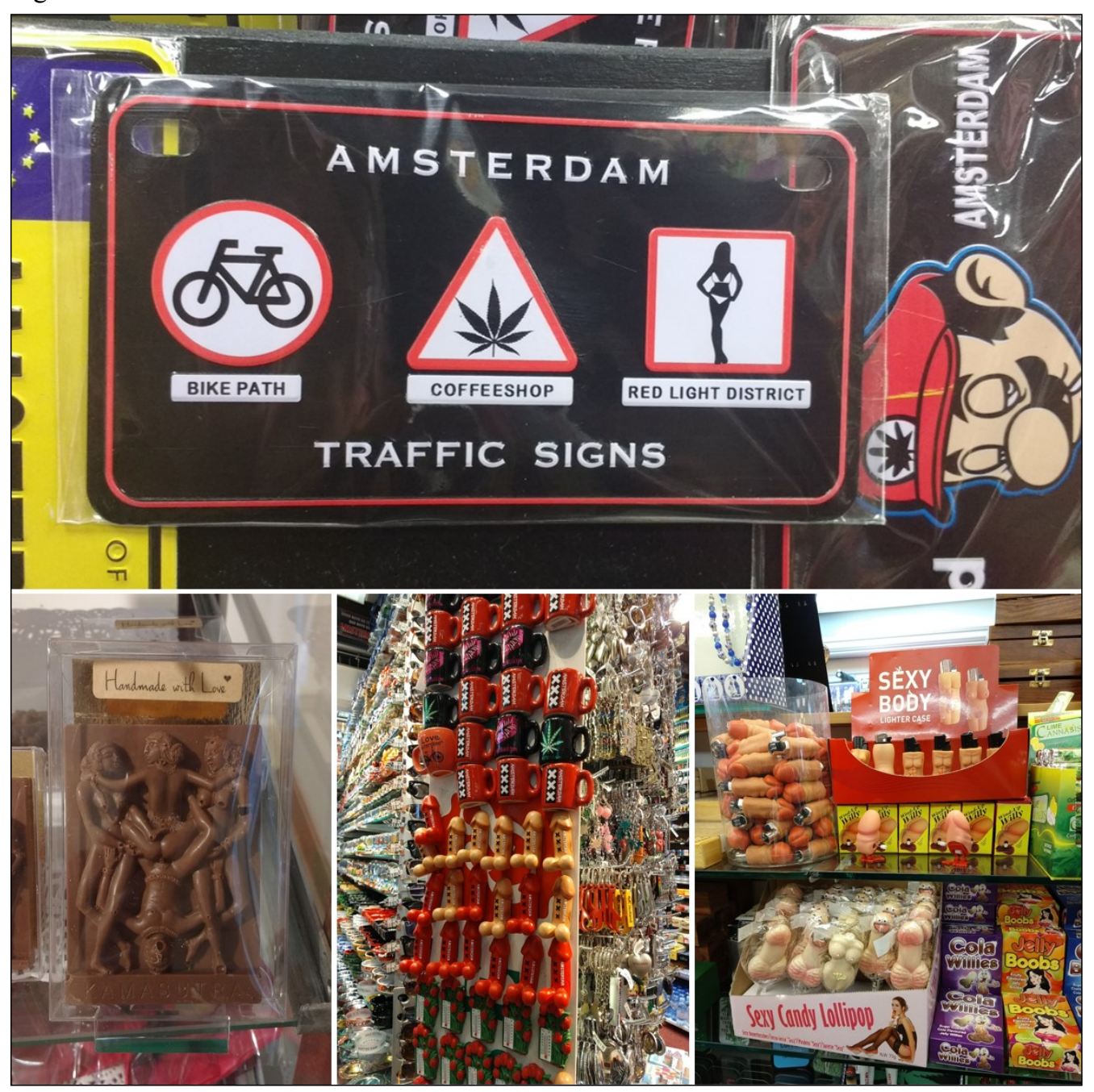

Fonte: Acervo do Autor (2018).

A imagem da cidade, para Kevin Lynch (2011), tem relação com a percepção visual, portanto a morfologia e os objetos urbanos são fundamentais. Isto depende da presença do observador na cidade em questão. Contudo, estamos falando de uma imagem de cidade que está no campo discursivo, na construção de uma ideia de cidade a partir tanto de sua materialidade quanto de elementos culturais e subjetivos (ZUKIN, 1996). 
Desse modo, a imagem de Amsterdã enquanto uma cidade liberal e progressista é uma narrativa difundida pela mídia, pelos visitantes do Red Light District, pela literatura etc. Isto faz com que alguém que nunca visitou ou morou em Amsterdã tenha o desejo de visitar a cidade onde tudo seria possível, onde tudo seria livre.

Em seu texto "How libertine is the Netherlands", o antropólogo holandês Gert Hekma (2005) questiona quão progressista é a Holanda. Se comparada a outros países do Ocidente, a Holanda possui diversas políticas públicas muito mais progressistas. Entretanto, o autor atribui isto ao pragmatismo holandês e ao limitado respeito às minorias. Segundo o autor:

O liberalismo sexual dos holandeses é um fenômeno superficial. Por trás dessa fachada, os holandeses são quase tão restritos em suas noções de prazer sexual quanto os americanos, russos ou ingleses (HEKMA, 2005, p. 220, tradução livre).

Adicionalmente, apesar de terem seu trabalho regulamentado há 20 anos, as prostitutas ainda enfrentam o "estigma de puta" que, conforme explicado por Gail Pheterson (1996), é uma marca de vergonha perante a sociedade. Assim sendo, a imagem de Amsterdã não se reflete na forma como as prostitutas são vistas pela sociedade, uma vez que elas ainda precisam reivindicar a legitimidade de seu trabalho, seus direitos e, em última instância, sua humanidade (PENA, 2020). A imagem da cidade enquanto discurso, portanto, não reverbera na mesma intensidade no cotidiano.

Outro elemento importante na configuração da paisagem urbana do bairro é a ausência de homens nas vitrines de prostituição. Embora não haja qualquer proibição da atuação masculina, as vitrines são ocupadas por mulheres cis, majoritariamente, e transgêneras. Os trabalhadores sexuais masculinos atuam em outros arranjos, como nos teatros de sexo ao vivo e casa de peepshow, existentes no próprio bairro, na internet etc. (PENA, 2020). Desse modo, a geografia da prostituição do Red Light District é marcada pela presença e visibilidade dos corpos femininos nas vitrines, sendo assim um lugar generificado. De igual modo, a imagem que circula sobre o Red Light District é relacionada não à prostituição simplesmente, mas à prostituição feminina, de modo que a questão de gênero tem um papel importante nesse processo.

Apesar da regulamentação, a prostituição continua sendo um campo de batalha em Amsterdã. A importância que esta atividade representa para o setor do turismo internacional e para a própria imagem da cidade tem sido, agora, vista pela municipalidade como um problema. Nesse sentido, o município tem atuado para diminuir o papel da prostituição em Amsterdã por meio de intervenções urbanas e também de ações de marketing urbano, como veremos adiante.

\section{Plano 1012: a "Renovação Urbana" do Coração da Cidade}

Em 2007 a Prefeitura de Amsterdã lançou um plano com ações voltadas ao centro da cidade, uma área importante na dinâmica urbana, bem como no mercado turístico. $\mathrm{O}$ centro de Amsterdã é uma área de uso misto, abrigando prédios residenciais, estabelecimentos comerciais, uma série de serviços e 
também o Red Light District, que abriga o mais famoso e visível tipo de trabalho sexual na cidade: a prostituição. É no centro que se localiza a Amsterdam Centraal, principal estação ferroviária que conecta Amsterdã aos demais municípios da Holanda e outros países. Caracterizada por sua paisagem urbana com seus canais e patrimônio arquitetônico que remontam ao período medieval, a área central da cidade passou a atrair grande atenção e ser foco de intervenções no fim dos anos 2000.

Tendo como principal justificativa a necessidade de combater a criminalidade na área central, o Plano 1012 foi lançado ainda em 2007, sendo nomeado em referência ao Código de Endereçamento Postal (CEP) da área, abrangendo não apenas o principal Red Light District, ou De Wallen, mas também áreas comerciais importantes (Kalverstraat-Nieuwendijk e DamrakRokin), um pequeno Red Light District próximo à Spuistraat, bem como sua vizinhança (AALBERS e DEINEMA, 2012; AMSTERDAM, 2008). O centro, com evidente foco no De Wallen, foi considerado uma área onde o índice de criminalidade estaria demasiado elevado e que a infraestrutura existente era a base para a manutenção de atividades ilegais. Os estabelecimentos ligados à indústria do sexo e os coffeeshops foram considerados naturalmente propensos ao crime, ignorando-se que se trata de dois setores legais e regulados por leis nacionais e municipais (AMSTERDAM, 2008; PENA, 2020).

Apesar de o plano apontar a criminalidade como principal problemática na área, evidenciando negócios da indústria do sexo que estariam envolvidos com atividades ilegais, as propostas apresentadas não deixam claro como combater efetivamente tal questão. Por outro lado, os objetivos e proposições apontam para uma tentativa de "renovação" da área e as principais ações do projeto dizem respeito aos interesses econômicos que rondam o centro da cidade, mais especificamente, o Red Light District, devido à sua infraestrutura, seu patrimônio arquitetônico e cultural e à sua importância para a imagem turística de Amsterdã etc.

Nesse sentido, os interesses econômicos parecem muito mais relevantes do que o combate à criminalidade. Segundo a publicação, o plano tem 5 objetivos, dentre os quais o combate à criminalidade e a melhoria da qualidade da imagem do centro.

Em resumo, temos cinco objetivos concretos:

1. Queremos desmontar a infraestrutura criminal.

2. Queremos reduzir o número de empresas sujeitas a influências criminais.

3. Queremos acabar com a negligência e decadência do centro e reverter isso.

4. Queremos restaurar o equilíbrio para os negócios da área.

5. Queremos obter uma imagem diversificada e de alta qualidade para a cidade (AMSTERDAM, 2008, tradução livre).

O documento do plano evidencia a posição de Amsterdã como uma importante cidade na Europa e a necessidade de atrair empreendedores e visitantes (AMSTERDAM, 2008). Ela está inserida num mercado global de cidades e, mais especificamente, num mercado de turismo internacional, o que a faz competir com outras cidades por investimentos e visitantes. Nesse 
sentido, como afirma Carlos Vainer (2000), a cidade passa a ser considerada uma mercadoria de luxo num mercado competitivo, no qual é preciso oferecer sempre as melhores condições para se manter na disputa.

Para obter o consenso necessário para o planejamento estratégico que se almejava, o discurso de combate à criminalidade caiu como uma luva. Isto porque é necessário criar um contexto de crise em que haja consenso a respeito da necessidade e pertinência de determinado projeto, neste caso do Plano 1012, pois "o plano estratégico supõe, exige, depende de que a cidade esteja unificada, toda, sem brechas, em torno do projeto" (VAINER, 2000, p. 91). Ao utilizar o tráfico de mulheres para fins de prostituição como principal razão para realizar intervenções no centro e fazer uso da mídia para disseminar isto para a população, a municipalidade agiu com perspicácia, afinal qual cidadão seria contrário a combater tal crime? Entretanto, apesar de obter algum apoio popular, o projeto também recebeu críticas que questionavam o real objetivo das intervenções (PENA, 2020).

Apesar dos problemas alegados, a Prefeitura de Amsterdã reconhece que "é o centro da cidade, junto com o Red Light District, que dá a Amsterdã a imagem de uma cidade tolerante, contrária e liberal. Liberdade acima de tudo!" (AMSTERDAM, 2008, tradução livre). Diferente do que argumentam Wonders e Michalowski (2001), Amsterdã admite oficialmente a importância do Red Light District, portanto da prostituição e da indústria do sexo, como aspecto basilar para sua imagem enquanto uma cidade tolerante, progressista e liberal.

Como afirma Paola B. Jacques, os projetos de "renovação urbana" no âmbito do planejamento estratégico "[...] precisam seguir um modelo internacionalmente homogeneizador, imposto pelos financiadores multinacionais dos grandes projetos de revitalização urbana" (JACQUES, 2004, p. 24). É isto que se observa nas propostas feitas pelo Plano 1012 para o Red Light District com a substituição de vitrines de prostituição e coffeeshops por lojas, galerias, cafés, restaurantes etc. A motivação econômica do plano aparece explicitamente na descrição da visão para o futuro do centro, especificamente na área entre Damrak e Rokin: "nossa intenção para a imagem nessa área é transformá-la num centro internacional de varejo. Haverá hotéis e lojas de excelência que oferecem produtos de alta qualidade" (AMSTERDAM, 2008, tradução livre).

Com a substituição das vitrines e outros empreendimentos da indústria do sexo por outros negócios, busca-se a implantação de empreendimentos de alto padrão e serviços exclusivos para um público abastado, assim "quem procura qualidade terá suas necessidades atendidas com produtos exclusivos de moda, mídia e estilo de vida" (AMSTERDAM, 2008, tradução livre). Com relação ao Red Light District, o plano afirma que "a seleção de lojas, empresas, hotéis, restaurantes e cafés deve ser de melhor qualidade e mais variada do que é hoje" (AMSTERDAM, 2008, tradução livre). Portanto, o interesse da municipalidade estava na melhoria da qualidade da área central para fins econômicos (ZUCKERWISE, 2016).

O Plano 1012 tinha 9 projetos âncora, entre eles a Chinatown - como é conhecida a rua Zeedijk, a Oudekersplein, os hotéis Victoria Hotel e o Grand Hotel Krasnapolsky etc. (AMSTERDAM, 2008; PENA, 2020). Parte desses 
projetos era da iniciativa privada - como os hotéis - que se beneficiou diretamente dos investimentos públicos na área. O luxuoso Grand Hotel Krasnapolsky, por exemplo, era um dos parceiros do projeto e reservou a quantia de 120 milhões de euros para investir na área da intervenção, evidenciando que o setor privado já tinha planos de investimentos na área antes da realização do Plano 1012, porém a realização desse projeto pela municipalidade pavimentou o caminho para que as empresas privadas pudessem efetivar seus projetos.

Devido à importância da prostituição para a imagem da cidade e a dinâmica turística, não se pretendia eliminá-la completamente da área, mas buscar um equilíbrio entre distintos tipos de estabelecimentos e um pretenso aumento da diversidade no local. O plano afirma:

Em nossa opinião, o red-light district deveria manter a combinação de edifícios residenciais e de escritórios com a vida noturna; uma mistura de chic e shady. A prostituição que é tão característica dessa área permanecerá em parte, mas sem o crime que está presente demais no momento (AMSTERDAM, 2008, tradução livre).

O fechamento das vitrines foi considerado como a solução para o problema da criminalidade e do tráfico de mulheres para fins de prostituição, sem que medidas mais específicas e adequadas fossem implementadas: para onde iriam as prostitutas que perderam seus locais de trabalho? $\mathrm{O}$ que aconteceria com uma vítima de tráfico ao deixar as vitrines que foram fechadas? Como afirmou Gabriela Leite (2006, p. 30), "prostitutas sempre estão em áreas a serem revitalizadas. Quando vem a revitalização, são as primeiras a serem expulsas", pois se tornam indesejadas e incompatíveis com a nova paisagem almejada. Se, como afirma Vainer (2012), no planejamento estratégico a miséria passa a ser considerada um problema ambiental e paisagístico, no caso do Plano 1012 a prostituição foi vista como uma mácula na paisagem do bairro e na imagem da cidade.

De acordo com o relatório da avaliação do Plano 1012, feita pelo Tribunal Metropolitano de Amsterdã (Rekenkamer Metropool Amsterdam), entre 2007 e 2018 foram fechadas 112 vitrines - restando $358 \mathrm{em}$ funcionamento - e também 26 coffee shops, além de sexshops, lojas de souvenir, casas de massagem, entre outros. Nos imóveis onde funcionavam foram instalados novos empreendimentos, como: lojas de doces, cafés, restaurantes, unidades residenciais, empresas turísticas, lojas de fast food etc. Os novos empreendimentos estão voltados, sobretudo, à demanda turística que cresceu vertiginosamente no bairro na última década. A diversidade almejada pelo plano, na verdade, resultou numa homogeneização dos negócios do bairro, sobretudo no caso das inúmeras lojas de fast food a preços baixos em vez dos restaurantes sofisticados prometidos (AMSTERDAM, 2018; PENA, 2020).

Apesar das mudanças, a prostituição continua sendo importante no bairro. Muitos turistas não buscam os serviços sexuais, querem apenas observar as prostitutas em seus locais de trabalho. Como explica Jan Nijman (1999, p.150, tradução livre), "[...] a imagem da cidade em si pode constituir um item de consumo cultural nesse intercâmbio global." Nesse sentido, a implementação do Plano 1012 e a reorganização da geografia da prostituição não foram 
suficientes para mudar a imagem da cidade, ou seja, para reduzir de forma relevante o papel da prostituição na atração de turistas. Então, o marketing urbano passou a ser utilizado pelo município a fim de reposicionar Amsterdã no contexto internacional.

\section{Marketing Urbano e Imagem da Cidade}

"O Marketing é agora o instrumento de controle social, e forma a raça impudente de nossos senhores" (DELEUZE, 1992, p. 224).

A cidade de Amsterdã possui sua própria "empresa" de marketing, a Amsterdam \& Partners ${ }^{1}$, responsável por promovê-la dentro e fora do país. Trata-se de uma organização sem fins lucrativos, financiada por recursos públicos municipais e da iniciativa privada local. Cabe a esta instituição cuidar da imagem da cidade e desenvolver campanhas de publicidade para a atração de turistas e investidores. Foi ela a responsável pelo desenvolvimento de uma nova marca para Amsterdã no início dos anos 2000. Como vimos, o Plano 1012 tinha como um de seus principais objetivos melhorar a imagem da cidade, mas ele foi apenas uma peça numa engrenagem que começou a girar anos antes com a intenção de reposicionar Amsterdã no contexto internacional. Segundo Kavaratziz e Ashworth (2007) a cidade estava perdendo espaço entre as principais cidades europeias.

Como vimos, a imagem de Amsterdã no contexto internacional está intimamente relacionada a uma ideia de liberalismo, ancorada, sobretudo, na tolerância às drogas e às vitrines de prostituição. Contudo, desde o começo dos anos 2000 tem havido um esforço no sentido de redirecionar o foco para outros aspectos da cidade. Isto começou antes do lançamento do Plano 1012 e continua a ser feito após sua finalização, mudando-se, contudo, as estratégias adotadas em distintos momentos. Kavaratziz e Ashworth (2007) explicam que em 2003 a Prefeitura de Amsterdã realizou um estudo para identificar as características que seriam apontadas pelos moradores como elementos únicos que distinguiriam a cidade. Essa pesquisa foi feita com base nas experiências de marketing de cidades consideradas as maiores concorrentes de Amsterdã: Barcelona, Berlim, Dublin e Roterdã.

A pesquisa revelou que uma associação forte entre a cidade, sexo e drogas não era algo desejável. Se nos anos 1990 o debate levou à regulamentação do trabalho sexual em 2000, apenas três anos depois esta era considerada uma característica negativa e indesejada da cidade. A partir daí um grande esforço foi feito no sentido de desenvolver uma marca (brand) que refletisse o que são considerados os valores fundamentais (core values) locais: criatividade, inovação e espírito comercial. Atrelado a isso foi lançada em 2004 a marca " $I$ Amsterdam", que atualmente é amplamente utilizada não apenas em peças publicitárias, mas também em souvenirs (KAVARATZIZ e ASHWORTH,

\footnotetext{
1 ? Cf.: Site da empresa Amsterdam \& Partners disponível em: $<$ https://www.iamsterdam.com/nl>. Acesso em: 11 mar. 2020.

2 ? Kavaratziz e Ashworth (2007) apresentam mais detalhadamente o processo que levou à criação da marca "I Amsterdam".
} 
2007). Além disso, havia um letreiro com a logomarca "I Amsterdam" na Museumplein (Praça do Museu), em frente ao Rijksmuseum (Museu Nacional), onde turistas tiravam fotos para registrar sua passagem pela cidade (Figura 4). Em dezembro de 2018 o letreiro foi removido da Museumplein sob a justificativa de que isto atraía muitos turistas para uma área com espaço limitado. O letreiro, que agora é itinerante, é considerado um símbolo do turismo de massa, cujos efeitos negativos têm sido sentidos pela população, sobretudo das áreas onde estão os mais importantes pontos turísticos (ADAMS, 2018).

Figura 4: Letreiro I amsterdam no Museumplein

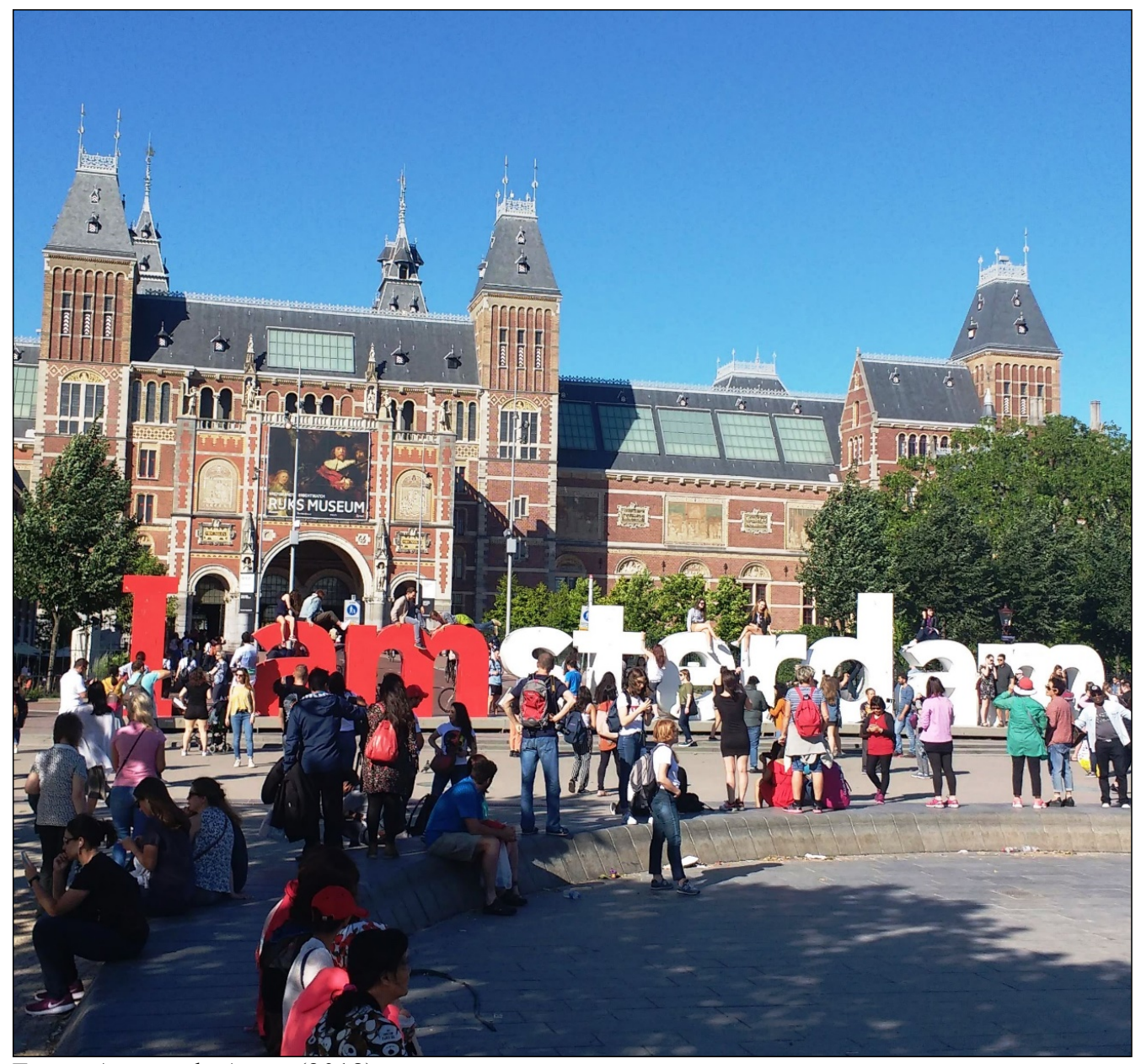

Fonte: Acervo do Autor (2018).

O esforço no sentido de mudar a imagem da cidade foi continuado pela implantação do Plano 1012, mas também em paralelo com outras iniciativas capitaneadas pela Amsterdam \& Partners. De acordo com Nico Mulder, responsável pelo departamento de estratégia de marketing, por volta de 2011, quando ele ingressou na empresa, o grande desafio era atrair visitantes, então foram feitas campanhas em âmbito internacional para alavancar a cidade até 2015 aproximadamente. Como vimos anteriormente, essas ações surtiram efeito e a cidade passou a ficar superlotada de turistas, sobretudo no centro. Entretanto, o número crescente de turistas passou a ser incômodo para os moradores, sendo necessárias outras ações para equalizar a situação. 
Segundo Nico Mulder, Amsterdã atrai 17 milhões de visitantes anualmente, sendo cerca de 7 milhões nacionais e 10 milhões internacionais (AMSTERDAM, 2016). Desse total, cerca de 50\% visitam a cidade pela primeira vez, então querem conferir alguns dos atrativos, sendo o Red Light District um dos cinco principais. Apesar disso, ele não é sequer mencionado no encarte que apresenta os resultados da pesquisa sobre os visitantes da Área Metropolitana de Amsterdã de 2016, realizado pelo Amsterdam Marketing (AMSTERDAM, 2016). De acordo com Nico Mulder, os esforços atualmente são direcionados não a atrair mais pessoas, mas sim o "tipo certo de visitante". Nesse sentido, ele faz uma distinção entre turista e o que chamou de visitante. Para ele turista estaria relacionado a algo negativo, às pessoas que fazem barulho, incomodam, jogam lixo na rua, bebem demais etc. enquanto o "tipo certo de visitante" seria aquela pessoa que permanece na cidade por pelo menos cinco ou seis dias, está interessada em outros aspectos da cidade além do centro - como os inúmeros museus - ou seja, buscam algo além de "sexo, drogas e rock 'n' roll'.

Se, por um lado, a distinção entre turista e visitante parece problemática, por outro, ela se encaixa exatamente no propósito de reposicionar a cidade e atrair pessoas com maior poder aquisitivo e/ou interessadas em características da cidade consideradas desejáveis, agradáveis ou motivos de orgulho. Nesse discurso, os turistas problemáticos - quase de forma essencializada - estão diretamente associados ao Red Light District, que tem aparecido sempre como um problema. A solução para isto contaria, então, com ações que visam não apenas intervir na infraestrutura em si, mas também a partir da definição de que tipo de pessoa é desejável - ou bem-vindo - e aquele que se quer evitar. Vimos que em termos de configuração urbana isto foi buscado pelas alterações feitas no bojo do Plano 1012, mas em termos de marketing urbano isso se dá pela promoção de determinadas qualidades da cidade de acordo com o público esperado. Nico Mulder explicou que isso tem sido realizado da seguinte maneira:

Nós dizemos que temos esse DNA de Amsterdã: criatividade, inovação e espírito comercial; e para mostrar esse DNA usamos icones, histórias, pessoas ou eventos relacionados a ele e somos nós quem decide quais icones, histórias ou eventos... Então, por exemplo, a história de que tivemos a primeira bolsa de valores do mundo, foi a primeira do mundo, foi fundada em Amsterdã, então, para nós, esse é um verdadeiro exemplo desse DNA. Nós não gritamos "somos criativos, temos inovação e temos espírito comercial", mas usamos histórias para mostrar e provar isso e, ao fazê-lo, podemos influenciar a percepção das pessoas. Isso é basicamente criar uma marca (branding) e é o mesmo quando não usamos "fume um baseado, visite Amsterdã", mas falamos sobre a tolerância e o nível de liberdade que temos em Amsterdã e porque isto se relaciona com o DNA. A construção dos canais é basicamente a mesma história. Então, criar uma marca para nós é realmente influenciar a percepção das pessoas [...] (Nico Mulder, entrevista, 25/01/2018, tradução livre). 
Como disse Deleuze (1992), o marketing como instrumento de controle social é mobilizado para direcionar, atrair ou ao menos estimular fluxos de negócios e de consumo a partir de determinados critérios, objetivos e interesses, em outras palavras, criar a "necessidade" de se conhecer determinado lugar ou consumir dado produto ou serviço. No caso de Amsterdã, isto tem sido feito de modo a diminuir a importância da prostituição, diminuir o interesse pela cidade por aqueles que são considerados indesejados e, por outro lado, atrair o perfil de visitante ideal. Como vimos, isto busca redirecionar a atenção do visitante para aspectos que estão alinhados com a imagem que a cidade deseja criar ou reforçar. Uma espécie de controle se dá não por uma imposição ou restrição, mas pelo estímulo que é feito em relação a esses atrativos e às possibilidades de se efetuar uma vigilância sobre esses corpos.

Apesar de ser legal e regulamentada, a prostituição atualmente não é considerada tão desejável, uma vez que tem sido retratada de forma negativa e as ações tem visado diminuir sua importância no centro e na imagem da cidade. Inclusive, segundo notícias recentes veiculadas pela mídia, a utilização da nomenclatura "Red Light District" em placas de sinalização, indicando a localização da área, entrou em debate. Para o vice-prefeito, Victor Everhardt, a utilização dessa terminologia transmite uma ideia inadequada: "eu acho que é uma escolha muito infeliz. Ela tem conotações indesejáveis e eu acho que o resultado será não usarmos mais essas palavras" (HET PAROOL, 2019, tradução livre). Nesse caso, a denominação tradicional "Wallen" ou mesmo "centro da cidade" são consideradas mais adequadas, o que também resultaria na redução do destaque da prostituição e da indústria do sexo no espaço intraurbano de Amsterdã. Há, então, várias indicações de que a prostituição tem sido tratada numa perspectiva mais conservadora nos últimos anos, mas isto não parece abalar a autopercepção holandesa. Ao comentar as restrições impostas ao aluguel de imóveis pelo Airbnb ${ }^{3}$ como medida para conter o turismo de massa - limite de até 60 dias, com previsão de redução de 30 dias em 2019, e apenas 4 pessoas por imóvel - Nico Mulder afirma: “[...] nós ainda somos liberais (open-minded). Sim, você ainda pode fazer muitas coisas aqui, mas até certo ponto e talvez com algumas restrições e condições" (Nico Mulder, entrevista, 25/01/2018, tradução livre). O que ele chama de liberal é muito mais uma postura pragmática, no sentido de resolver um problema de forma mais prática: regulamentar, definir critérios, impor restrições e limites etc.

Se no âmbito local o marketing tenta tirar a atenção que a prostituição detém, no contexto nacional isto não parece se dar da mesma forma. Em 2018 foi realizada a $16^{\mathrm{a}}$ Bienal de Arquitetura de Veneza, na qual o Pavilhão Holandês teve como tema "Trabalho, corpo, lazer" (Work, body, leisure). Um livro homônimo foi publicado em conjunto com o Pavilhão discutindo arquitetura e articulando os três tópicos da exposição com as questões das tecnologias empregadas na sociedade contemporânea, a automatização das

$3 \mathrm{O}$ crescimento do número de aluguéis pela plataforma Airbnb tem sido um assunto em debate em Amsterdã, onde a disponibilidade X demanda por imóveis já é uma questão delicada. 
cidades e a relação corpo e máquinas. Uma das editoras do livro e curadora do Pavilhão Holandês na bienal, Marina Otero Verzier afirma que:

Refletindo sobre esse espectro de espaços e pontos de vista teóricos, Trabalho, Corpo e Lazer visa oferecer visões que podem ser implantadas na remodelação de estruturas de trabalho contemporâneas e futuras e, por fim, nossa capacidade de redesenhá-las de acordo com um diferente conjunto de princípios éticos (VERZIER, 2018, p. 70, tradução livre).

Um dos capítulos do livro é intitulado "Sexo à venda" (Sex for sale), de autoria de Annemarie de Wildt (2018), historiadora e curadora do Amsterdam Museum, que escreveu um ensaio rico em fotografias que apresenta um panorama do trabalho sexual no país com ênfase no Red Light District de Amsterdã, que é o principal expoente da atividade no país. A partir da análise de pinturas e fotografias, a autora discute a presença das prostitutas no país e aponta mudanças na arquitetura dos espaços onde elas têm atuado ao longo dos anos. Além disso, a autora rapidamente menciona a implantação do Plano 1012 com tom crítico à substituição da prostituição nas vitrines por artistas, designers, além dos outros serviços anteriormente mencionados. $\mathrm{O}$ aspecto importante disso é a inserção da prostituição como um elemento de destaque na bienal de arquitetura, que é uma espécie de vitrine internacional do país. Com relação às vitrines características do Red Light District, Marina Otero Verzier afirma que:

Seus interiores modernistas, projetados racionalmente e revestidos com azulejos brancos e regulares e equipados com camas de solteiro fixas, bidês, pias e o armário onipresente, descrevem não apenas um espaço de trabalho eficiente, mas também a transformação de um corpo em uma trabalhadora (VERZIER, 2018, p. 67, tradução livre).

Ao apresentar a prostituição - de forma justa e acertada - enquanto um trabalho, analisando as mudanças na arquitetura dos espaços laborais, a narrativa apresentada na exposição (a partir da análise do livro) indica uma divergência com a maneira como essa atividade tem sido encarada pelo município de Amsterdã. Se, por um lado, no âmbito local vimos que tem havido inúmeros esforços no sentido de fazê-la encolher no tecido urbano, perder importância na dinâmica e na imagem da cidade, por outro, é significativo que a prostituição tenha sido escolhida entre tantas outras atividades laborais para se discutir as implicações da arquitetura na vida dos trabalhadores e a relação destes com as tecnologias. Pelo menos em termos de imagem e marketing internacional, isso denota mais uma entre tantas contradições e conflitos existentes em relação à prostituição em distintas escalas e contextos na Holanda.

\section{Conclusão}

Diferente do que se pode imaginar a partir do que costuma ser difundido sobre a prostituição em Amsterdã, cujo Red Light District é uma das zonas de comércio sexual mais conhecidas do mundo, esta área continua sendo um 
campo de batalha. Pena (2019a) já mostrou como a trajetória da prostituição na cidade é marcada por rupturas, descontinuidades e enfrentamentos, mas também importantes conquistas para as prostitutas. Contudo, a implementação do Plano 1012 descortina um novo capítulo nesse campo de disputas que é o Red Light District. Autorizadas a funcionar legalmente desde 2000, parte significativa das vitrines foi fechada entre 2007 e 2018, além de outros estabelecimentos, como sexshops e coffeeshops, também característicos da área. Sob a justificativa de combater a criminalidade presente no bairro, a prefeitura empreendeu uma verdadeira cruzada contra a indústria do sexo, propondo alterações profundas no bairro no bojo do Plano 1012.

Se, por um lado, alegou-se a necessidade de combater a criminalidade, por outro lado, ficou evidente o interesse em realizar uma higienização social, uma limpeza da área. Isto abriria espaço para investimentos em produtos e serviços de maior qualidade voltados para um público mais abastado. A diversidade característica dessa área da cidade não se alinhava mais com a imagem que se pretendia para Amsterdã. Contudo, apesar de terem sido realizadas intervenções e melhorias e muitas vitrines e coffeeshops terem sido fechados, a presença massiva de fast foods revela que o plano não foi exitoso em atrair restaurantes sofisticados.

Considerando o contexto atual, o Plano 1012 revela a ambição do município de se tornar ainda mais competitivo e atrair investimentos nacionais e internacionais, então a prostituição era encarada como um empecilho para os objetivos almejados. Assim, a "renovação urbana" de seu bairro mais simbólico foi usada como dispositivo para "melhorar" a imagem de Amsterdã, projetá-la e reposicioná-la no mercado global de cidades. Aliado a isto, as ações de marketing da cidade de Amsterdã têm buscado, por um lado, dar mais visibilidade a outros atrativos da cidade e, por outro, diminuir a importância da prostituição e do Red Light District na imagem que é difundida sobre essa cidade. Entretanto, em nível nacional, a prostituição foi um dos temas abordados pela Holanda em seu Pavilhão da 16 ${ }^{\mathrm{a}}$ Bienal de Arquitetura de Veneza, evidenciando diferenças na forma como essa questão é tratada no que diz respeito à imagem de Amsterdã e da Holanda.

\section{Agradecimentos}

A pesquisa que deu origem a este artigo obteve apoio financeiro do Conselho Nacional de Desenvolvimento Científico e Tecnológico (CNPQ) e da Coordenação de Aperfeiçoamento de Pessoal de Nível Superior (CAPES). Agradeço especialmente à profa. Dra. Rachel Spronk por ter me acolhido e me supervisionado entre 2017 e 2018, quando fui Visiting PhD Fellow no Instituto para Pesquisa em Ciência Social de Amsterdã (AISSR), da Universidade de Amsterdã (UvA). 


\section{Prostitution and the City's Image of Amsterdam}

neighbourhood. There, tourists mingle with older residents, young student residents, sex workers, children, police officers doing their rounds, people passing by on bicycles and in cars, and so forth. The narrow streets of the neighbourhood are shared by the most diverse groups of people, speaking a wide range of languages, however, this is not necessarily a harmonious coexistence. Although the presence of sex work and drugs provides the area with its singular nature, over the years this dynamics has generated conflicts among those interested in it.

The history of sex work in the city is marked by changes and conflicts, as well as by tolerance and a continued presence. As a coastal city, Amsterdam always received many travellers and sailors that spent some time in the town. These visitors would seek entertainment in the brothels. However, despite the importance of sex work in the city's dynamics, over the centuries, it has been more tolerated than socially accepted.

In 1911, brothels were prohibited to operate, but they continued their activities under a certain "regulated tolerance". It was during the twentieth century that a more diversified sex industry flourished in Amsterdam, with a range of sex shops, clubs, live sex shows, porno cinemas, as well as the characteristic window brothels (Figure 1) concentrated in the city centre. This flourishing began in the late 1960s and early 1970s, when Amsterdam also experienced a political and cultural burgeoning (PENA 2019a; 2020).

Figure 1: Brothel Window in the Red Light District

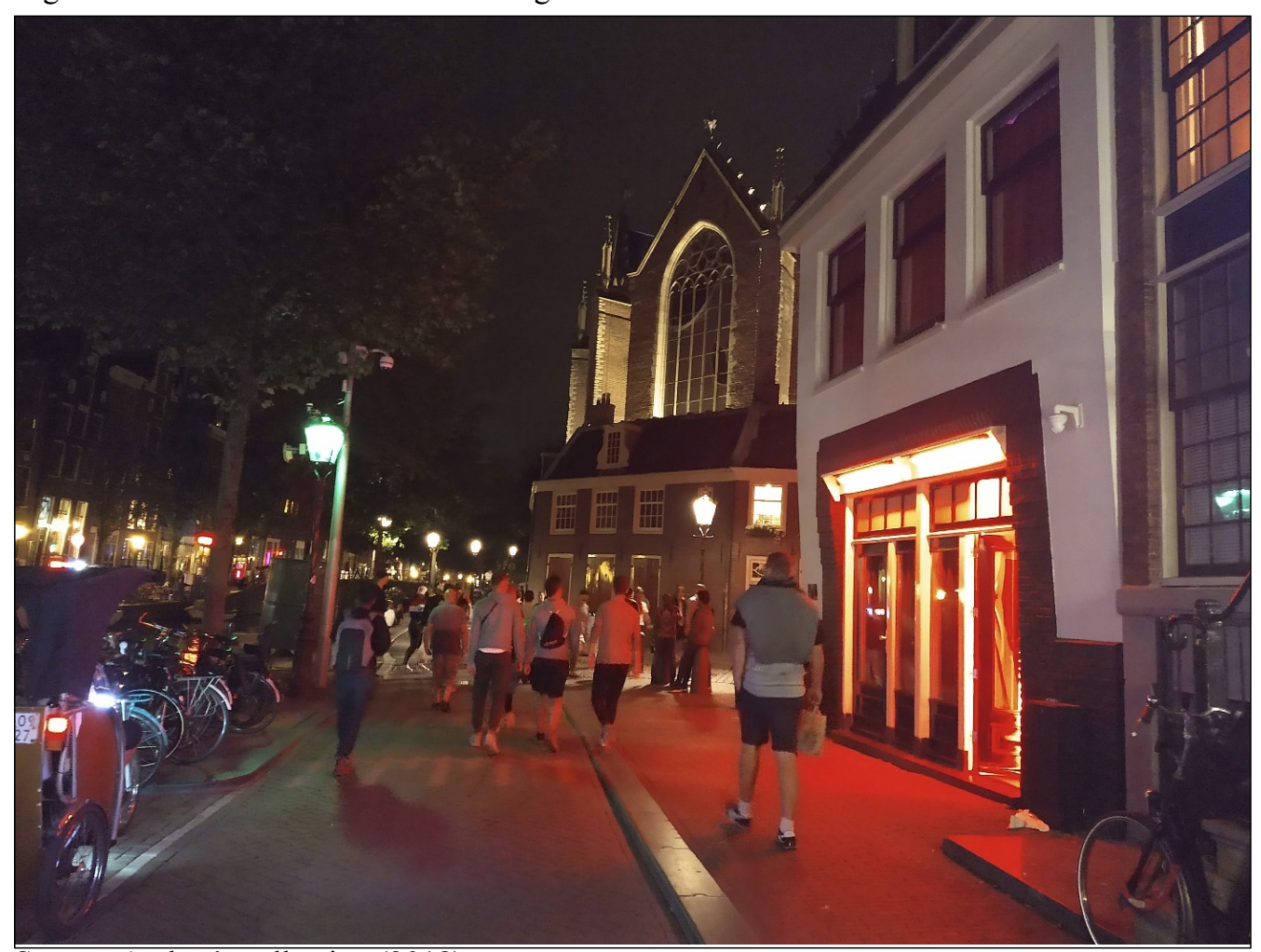

Source: Author's collection (2018).

The existence of sex work and sex-related establishments turned the Red Light District into one of Amsterdam's main sights, attracting tourists from all over the globe. Many tourists visit the area to discover one of the most famous sex work zones in the world, drink beer, smoke marijuana and have fun. Sex 


\section{Prostitution and the City's Image of Amsterdam}

work is evidenced in the city's landscape, not only due to the presence of sex workers displayed in windows, but also to the existence of a range of sex objects and images on the neighbourhood's walls (Figure 2). In their window displays, the sex shops shamelessly exhibit a plethora of sex objects, provoking the curiosity and interest of passers-by even before entering them.

Figure 2: Erotic images in the Red Light District

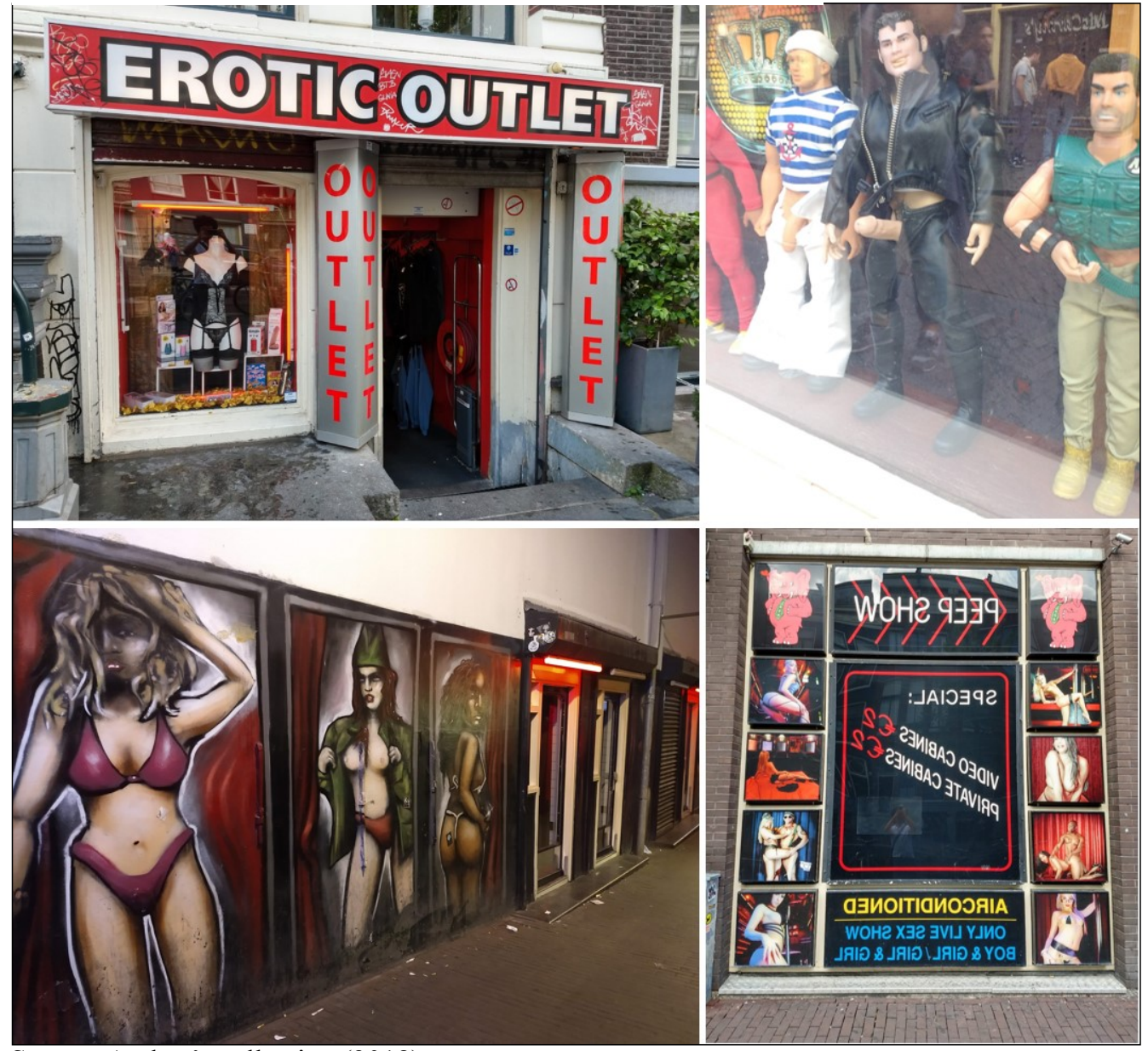

Source: Author's collection (2018).

The importance of sex work and the Red Light District for the city and for tourism can also been seen in souvenirs sold in the countless retail stores around the neighbourhood. A wide variety of objects can be found there, allowing the tourist to take home a souvenir as a memento of the city's most striking elements. Among the postcards and knick-knacks for sale in these shops, sex work and sex-related objects are usually displayed alongside bicycles, windmills, paintings by Dutch artists, tulips and so forth (Figure 3). In this way, the image of the city of Amsterdam is directly linked to sex work and to the idea that this is a liberal and progressive city (PENA, 2020).

These souvenirs attempt to capture Amsterdam, the capital and largest city in the country, which ends up being seen as the greatest symbol of freedom and progressivism, where issues such as sex work and the sale of drugs are easily observed in the configuration of its spaces and in its urban dynamics. In this sense, Jan Nijman (1999) explains that the notion of tolerance captured by the international tourism is different from that related to the diversity of its 
Prostitution and the City's Image of Amsterdam

population. Currently, the idea of tolerance ascribed to Amsterdam is primarily associated with how the city deals with drugs and sex work. That author notes that the latter corresponds to the expectations of tourists who visit the city, interested in doing and seeing things that are not permitted in many places. This is the image that circulates in most media, but which is also transmitted by the visitors themselves, since "[...] it is people themselves (not computers or television) that serve as media of information, as the global transmitters of the images of localities" (NIJMAN 1999, p.149). This is particularly relevant if we consider the possibilities of real time sharing provided by social networks and new information technologies.

Figure 3: Souvenirs sold in Amsterdam

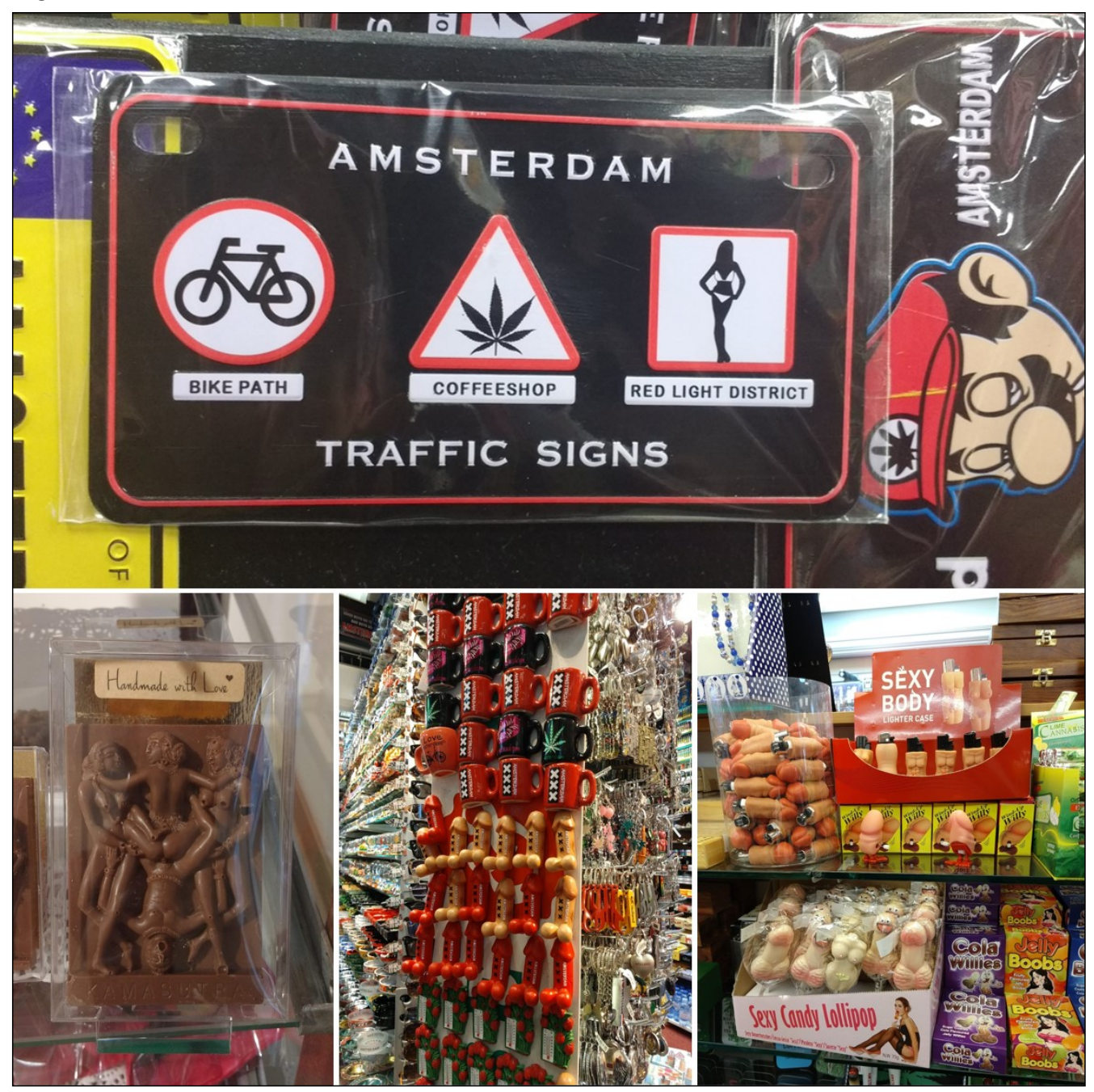

Source: Author's collection (2018).

According to Kevin Lynch (2011), a city's image is related to visual perception, therefore, the urban morphology and its objects are fundamental. This depends on the presence of the observer in such city. However, we are referring to the image of a city that is in the discursive field, in the construction of an idea of city from both its materiality and its cultural and subjective elements (ZUKIN, 1996). Thus, the image of Amsterdam as a liberal and progressive city is a narrative spread by the media, the Red Light District 
visitors, the literature, etc. This makes people who have never visited the city or lived in Amsterdam want to be in that place where everything seems to be possible, and freedom is everywhere.

In his text "How libertine is the Netherlands", the Dutch anthropologist Gert Hekma (2005) questions how progressive the Netherlands is. When compared to other Western countries, the Netherlands present several more progressive public policies, for example. However, that author ascribes that to the Dutch pragmatism and their limited respect to minority groups. According to him:

The sexual liberalism of the Dutch is a surface phenomenon only. Beneath this veneer, the Dutch are nearly as restricted in their notions of sexual pleasure as the Americans, Russians, or English (HEKMA, 2005, p. 220).

In addition to that, despite having their work legalized for over twenty years, sex workers still face the "whore stigma" which, as explained by Gail Pheterson (1996), is a shameful mark before society. Thus, the image of Amsterdam is not confirmed in the way sex workers are seen by its society, since they still need to claim the legitimacy of their work, their rights, and even their humanity (PENA, 2020). The city's image as discourse, therefore, does not echo with the same intensity in people's everyday life.

Another important element in the configuration of the urban landscape of that neighborhood is the absence of men in the brothel's windows. Although male sex work is not prohibited, the windows are occupied by cis women, mainly, and female transgender workers. Male sex workers have other professional arrangements, such as the live sex theaters and the peepshow houses in the same neighborhood, on the internet, etc. (PENA, 2020). Therefore, the sex work geography in the Red Light District is marked by the presence and visibility of female bodies in the brothel windows, which become a gendered space. Likewise, the image of the Red Light District is not only related to sex work, but specifically to female sex work, revealing that the gender issue has a relevant role in this process.

Although sex work is regulated and brothels have been legally operating since the 2000s, sex work continues to be a battlefield in Amsterdam. The importance it has for the international tourism sector and for the city's image is now regarded by the municipality as a problem. It has therefore acted to reduce the role of sex work in Amsterdam, through urban interventions and urban marketing activities, as we shall see.

\section{Plan 1012: An “Urban Renovation" Plan for the Heart of the City}

In 2007, the municipality of Amsterdam launched an action plan aimed at the city centre, an important area in the urban dynamics, as well as for the tourism market. The centre of Amsterdam is a mixed-use area, including residential buildings, commercial establishments, a series of services and the Red Light District, which shelters the most famous and visible type of sex work in the city: prostitution. Amsterdam Centraal, the main railway station that connects Amsterdam to other municipalities in the Netherlands and to 
other countries, is located in the centre. Characterized by its urban landscape, with its canals and architectural heritage dating back to medieval times, the central area of the city began to attract significant attention and became the focus of interventions at the end of the 2000s.

The main justification for such interventions was the need to fight criminality in the central area, therefore, the Plan 1012 was launched in 2007. It gained its name from the area's postcode, which not only covers the main Red Light District, or De Wallen, but also important commercial areas (Kalverstraat-Nieuwendijk and Damrak-Rokin), a small Red Light District close to Spuistraat, as well as its neighbourhood (AALBERS and DEINEMA, 2012; AMSTERDAM, 2008). The centre, with evident focus on De Wallen, was considered an area with high crime rates and whose existing infrastructure was used as the base of illegal activities. The establishments linked to the sex industry and coffee shops were considered naturally prone to crime, ignoring the fact that these two sectors were legal and regulated by national and municipal laws (AMSTERDAM, 2008; PENA, 2020).

Although the plan suggests that criminality is the area's main problem, giving evidence of the sex industry business involvement in illegal activities, the proposals did not clarify how to combat this issue effectively. On the contrary, their aims and propositions suggest an attempt to "renovate" the area and the project's main activities refer to economic interests that surround the city centre, more specifically the Red Light District, due to its infrastructure, its architectural and cultural heritage and its importance for Amsterdam's image as a tourist centre, among other issues. In this sense, economic interests seem to be much more relevant than the fight against criminality. According to the plan publication, it had 5 objectives, which included the combat to criminality and the improvement of the quality of the city centre image.

In summary, we have five concrete aims:

1. We want to dismantle the criminal infrastructure.

2. We want to reduce the number of businesses that are subject to criminal influences.

3. We want to put a stop to the neglect and decay of the centre and turn it around.

4. We want to restore balance to the businesses in the area.

5. We want to realise a varied and high quality image for the city approach area (AMSTERDAM, 2008).

The document evidences Amsterdam's position as an important European city and the need to attract businesses and visitors (AMSTERDAM, 2008). It belongs to a global market of cities and, more specifically, the international tourism market, which competes for investment and visitors with other cities. In this sense, as Carlos Vainer (2000) asserts, the city began to be considered a luxury commodity in a competitive market, in which it had to provide the best conditions in order to remain in contention.

To obtain the necessary consensus for the desired strategic plan, the discourse of fight against criminality was just perfect. This occurred due to the need for the creation of a crisis context, so that a consensus regarding the necessity and pertinence of certain project is reached, in this case the Plan 
1012, since "the strategic plan supposes, demands, depends on the city being entirely united, without disparities, around the project" (VAINER, 2000, p. 91). By putting forward the sex trafficking of women as the main reason for undertaking interventions in the centre and using the media to disseminate this news, the municipality acted with perspicacity - after all, what kind of citizen would be against combatting such a crime? Although the project obtained some popular support, it also faced criticism from those who questioned the real purpose of such interventions (PENA, 2020).

Despite the problems reported, the Amsterdam city hall recognized that "it is the city's centre, together with the red-light district, that gives Amsterdam its image of a tolerant, contrary and liberal city. Liberty above all things!" (AMSTERDAM, 2008). Contrary to the arguments of Wonders and Michalowski (2001), Amsterdam officially admits the importance of the Red Light District, hence, of sex work and the sex industry, as basic aspects of its image as a tolerant, progressive and liberal city.

As stated by Paola B. Jacques, the "urban renovation" projects in the strategic plan scope "[...] need to follow an internationally homogenizing model, imposed by multinational financers from large-scale urban revitalization projects" (JACQUES, 2004, p. 24). This is observed in the proposals put forward by the Plan 1012 for the Red Light District with substitution of the brothels' windows and coffee shops with stores, galleries, cafes, restaurants, etc. The plan's economic motivation clearly appears in the description of the vision for the centre's future, specifically in the area between Damrak and Rokin: "our ambition for the image in this area is to have it develop into an international retail centre. There will be first-rate hotels and shops that offer high quality products" (AMSTERDAM, 2008).

By substituting the brothels' windows and other facilities of the sex industry with other businesses, the city seeks to install high quality businesses and exclusive services for a wealthy audience, thus "those looking for quality will have their needs satisfied with exclusive fashion, media and lifestyle products" (AMSTERDAM, 2008). As for the Red Light District, the plan states that "the selection of shops, businesses, hotels, restaurants and cafés should be of better quality and more varied that it is now" (AMSTERDAM, 2008). Therefore, the municipality's main interest was in improving the quality of the area with economic purposes (ZUCKERWISE, 2016).

The Plan 1012 had 9 anchor projects, which included the Chinatown - as the Zeedijk street is known, the Oudekersplein, the Victoria Hotel, and the Grand Hotel Krasnapolsky, etc. (AMSTERDAM, 2008; PENA, 2020). Part of these projects belonged to the private initiative - such as the hotels - which benefited directly from the public investments in the area. The luxurious Grand Hotel Krasnapolsky, for example, was a partner in the project and put aside 120 million euros to invest in the intervention area, evidencing that the private sector already had investment plans for the area, even before the launch of the Plan 1012; however, the development of this project by the municipality paved the way for the private businesses to implement their projects.

Due to the sex work importance for the city's image and the tourism dynamics, the municipality did not intend to completely eliminate this activity in the area, but rather sought to find a balance between different types of 
establishments, increasing the area's diversity. To achieve such objective, the plan explained:

In our minds, the red-light district should retain the combination of residential and office buildings with night-life; a mix of chic and shady. The prostitution that is so characteristic of this area will remain in part, but without the crime that is all too present at the moment (AMSTERDAM, 2008).

Closing the windows was considered a solution to the problems of criminality and traffic of women for sex work, without the implementation of more specific and suitable measures: where should the sex workers who had lost their jobs go? What would happen to the traffic victims when they had to leave the windows that were closed? As Gabriela Leite (2006, p. 30) asserted, "there are always sex workers in areas to be revitalized. When revitalization comes, they are the first to be expelled." This is because they become undesirable and incompatible with the newly desired landscape. If, as Vainer (2012) pointed out, in strategic planning, poverty is regarded as an environmental and landscaping problem, in the case of Plan 1012, sex work has been reconfigured into a blemish on the landscape of the neighbourhood and on the image of the city itself.

According to the Plan 1012 evaluation report, carried out by the Amsterdam Metropolitan Court (Rekenkamer Metropool Amsterdam), between 2007 and 2018, 112 windows were closed - while 358 remained in operation. Other businesses that were also closed included 26 coffee shops, some sexshops, souvenir shops, massage parlors, among others. Those facilities were occupied by other types of businesses such as candy shops, cafes, restaurants, residential units, tourist agencies, fast food restaurants, etc. The new businesses are mainly targeted at the neighborhood tourism demand, which showed a sharp increase in the last decade. The diversity advertised by the plan, in fact, resulted in the homogenization of the commercial activity in the neighborhood, mainly regarding the countless low-priced fast food restaurants, rather than the promised sophisticated restaurants (AMSTERDAM, 2018; PENA, 2020).

Despite the changes occurred, sex work is still an important activity in the neighborhood. Many tourists that go there do not seek sexual service; they just want to observe the sex workers in their workplace. As Jan Nijman (1999, p. 150) explains: "[...] the image of the city itself may constitute an item of cultural consumption in this global exchange." In this sense, the implementation of the Plan 1012 and the reorganization of the sex work geography have not been sufficient to change the city's image, in other words, to significantly reduce the role of sex work in attracting tourists. Thus, the urban marketing started to be used by the municipality to reposition Amsterdam in the international context.

\section{Urban Marketing and the City's Image}

"Marketing is now the instrument of social control and produces the arrogant breed who are our masters" (DELEUZE, 1992, p. 224). 
The city of Amsterdam has its own marketing company, Amsterdam \& Partners ${ }^{1}$, responsible for promoting it both within and outside the country. This is a non-profit organization, funded by public municipal resources and the local private initiative. The institution is responsible for taking care of the city's image and running publicity campaigns to attract tourists and investors. In the early 2000s, it was responsible for developing a new logo for Amsterdam. As previously mentioned, one of Plan 1012 main objectives was to improve the city's image, but this was only one component of the gears that had started turning years before, with the purpose of repositioning Amsterdam within the international context. According to Kavaratziz and Ashworth (2007), the city was losing ground to other major European cities.

As already pointed out, the image of Amsterdam in the international context is intimately linked to an idea of liberalism, above all anchored to the tolerance of drugs and prostitution windows. However, since the beginning of the 2000s, efforts have been made to redirect this focus to other aspects of the city. This began before the launch of the Plan 1012 and has continued after its completion, with the adopted strategies changing at different times. Kavaratziz and Ashworth (2007) explained that in 2003, the municipality of Amsterdam conducted a survey among its residents to identify those features that constitute unique elements to distinguish the city. The study was based on the marketing experiences of the cities considered to be Amsterdam's greatest competitors, namely, Barcelona, Berlin, Dublin, and Rotterdam.

The survey revealed that a strong association between the city, sex and drugs was not desirable. If, in the late 1990s, the debate led to the regulation of sex work, in 2000, only three years later, this was considered a negative and undesirable feature of the city. From that point onwards, a great effort was made to develop a brand that reflected what they considered to be their local core values: creativity, innovation and a commercial spirit. Coupled with this was the 2004 launch of the brand "I Amsterdam", which is now widely used, not only in publicity materials, but also in souvenirs (KAVARATZIZ and ASHWORTH, 2007). Furthermore, an "I Amsterdam" sign was erected in the Museumplein (Museum Square) in front of the Rijksmuseum (National Museum) where tourists took photos to register their trip to the city (Figure 4). In December 2018, the sign was removed from the Museumplein with the justification that it attracted tourists to an area of limited space. The lettering, which is now itinerant, is considered to be a symbol of mass tourism, whose negative effects have been felt by the population, particularly at the most important tourist sights (ADAMS, 2018).

Efforts to change the city's image continued with the implementation of Plan 1012, in parallel with other initiatives led by Amsterdam \& Partners. According to Nico Mulder, their Marketing Strategy Manager, when he joined the company in around 2011, the greatest challenge was to attract visitors and,

1 Cf:: Amsterdam \& Partners webpage available at: <https://www.iamsterdam.com/nl $>$. Access on: 11 Mar. 2020.

2 Kavaratziz and Ashworth (2007) outline in detail the process that led to the creation of the brand "I Amsterdam". 
Prostitution and the City's Image of Amsterdam

up to approximately 2015, campaigns were run at international level to promote the city. As previously described, these activities had the desired effect and the city started to receive crowds of tourists, particularly in the centre. However, the growing number of tourists started to bother the residents, and other actions were required to balance the situation.

Figure 4: Lettering I Amsterdam at the Museumplein

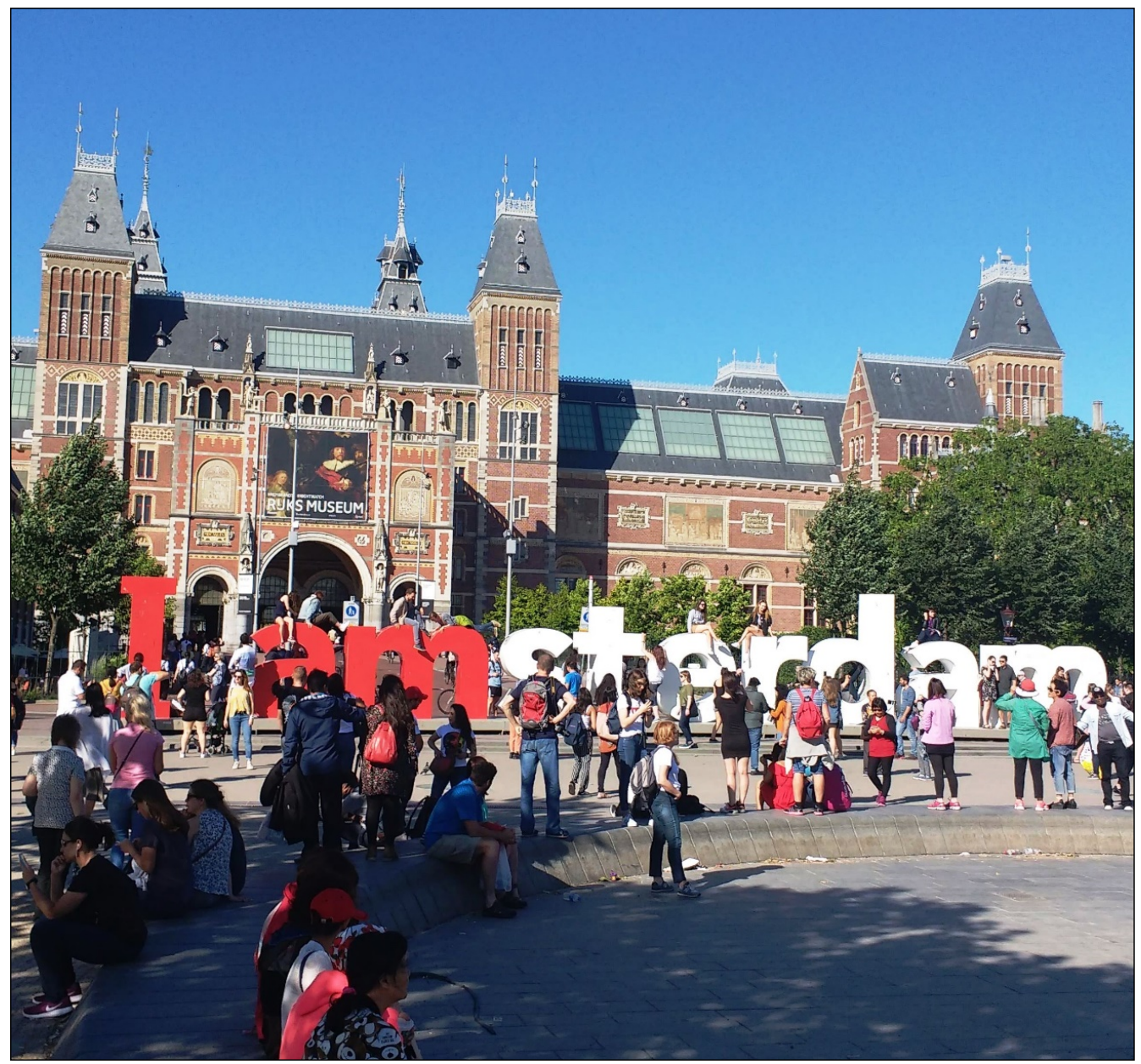

Source: Author's collection (2018).

According to Nico Mulder, Amsterdam attracts 17 million visitors per year, of whom approximately 7 million are domestic and 10 million are international (AMSTERDAM, 2016). Of this total, about 50\% are visiting the city for the first time and want to see certain attractions - for these visitors the Red Light District is one of the city's five main sights. Despite this, that neighbourhood is not even mentioned in the insert presenting the results of a survey about visitors to Amsterdam's Metropolitan Area, conducted by the Amsterdam Marketing (AMSTERDAM, 2016). According to Nico Mulder, current efforts are not aimed at attracting more people but rather the "right type of visitor". As regards to this characteristic, he makes a distinction between tourists and what he calls visitors. For him, tourists refer to something negative, people who make noise, are a nuisance, drop litter on the street, drink too much and so forth, while the "right type of visitor" is someone who remains in the city for at least five or six days, is interested in other aspects beyond the city centre - 
such as the countless museums - in other words, someone who is looking for something beyond "sex, drugs and rock and roll".

If, on the one hand, the distinction between tourist and visitor appears problematic, on the other, it fits precisely into the proposed repositioning of the city to attract people with greater purchasing power and/or interest in the features of the city that are considered desirable, pleasant, or a source of pride. In this discourse, problematic tourists - almost by their very nature - are directly associated with the Red Light District, which has also always been regarded as problematic. The solution then relies on activities not only aimed at intervening in the infrastructure itself, but also based on a definition of what type of person is desirable - or welcome - and those who should be avoided. We can see that, in terms of urban configuration, this was pursued through changes promoted by the Plan 1012, however, in terms of urban marketing, this is achieved by the promotion of certain features of the city according to the expected audience. Nico Mulder explains how this occurred:

- We say we have this DNA of Amsterdam: creativity, innovation and spirit of commerce; and to show this DNA we use icons, or stories, or persons or events that relate to this DNA and we are the ones to decide which icons or stories or events... So, for instance, the story we had about the world's first stock exchange, it was the world's first, it was established in Amsterdam, so, for us that's a true example of this DNA. We do not shout "we are creative, we have innovation and we have spirit of commerce" but we use stories to show it and to prove it, and by doing so, we can influence the perception of people. That's basically branding and that's the same when we don't use "smoke a joint, visit Amsterdam" but we tell about the tolerance and about the level of freedom we have in Amsterdam and because it relates to the DNA. Building up the canals, it's the same story, basically. So, branding for us is really about influencing the perception of people [...] (Nico Mulder, interview, 25/01/2018).

As Deleuze (1992) said, marketing as an instrument of social control is mobilized to direct, attract or at least stimulate flows of business and consumption based on certain criteria, objectives and interests, that is, to create the "need" to get to know a certain place or to consume a given product or service. In the case of Amsterdam, this has been aimed at diminishing the importance of sex work, diminishing interest in the city from those considered undesirable and, on the other hand, attracting the ideal visitor profile. As previously mentioned, this seeks to redirect the visitor's attention to aspects that are aligned with the image that the city desires to create or reinforce. It is a form of control that does not come about through imposition or restriction, but by stimulating these attractions and through the possibilities of practicing surveillance over these bodies.

Although sex work is legal and regulated, it is not considered desirable and has been portrayed negatively; therefore, activities have been aimed at reducing its importance in the centre and in the image of the city. According to news recently broadcast by the media, the use of the name "Red Light District" 
on signposts indicating the area's location has also been included in the debate. For the Deputy Mayor, Victor Everhardt, this terminology is not appropriate: "I think it's a very unfortunate choice. It has undesirable connotations, and I think the outcome will be that we won't use these words" (HET PAROOL, 2019). In this case the traditional name "Wallen" or even "city centre" are considered more appropriate, reducing the focus on sex work and on the sex industry in the Amsterdam's intra-urban space. There are several indications that sex work has been treated more conservatively in the city in recent years, but this does not appear to have shaken the Dutch people's self-perception. When commenting on restrictions imposed on Airbnb ${ }^{3}$ property rentals as a measure to contain mass tourism - a limit of up to 60 days, with a planned reduction to 30 days in 2019 and only four people per property - Nico Mulder asserts: "[...] we are still open-minded, yes, you can still do lots of things here, but to a certain extent and with some restrictions or conditions maybe" (Nico Mulder, interview, 25/01/2018). What he calls liberal is much more a pragmatic attitude to solving a problem in a more practical way: by regulating, defining criteria, imposing restrictions and limits, and so forth.

Even if the local marketing attempts to divert attention away from sex work, this does not appear to function in the same way in the national context. In 2018, at the 16th Venice Architecture Biennale, the theme of the Dutch Pavilion was "Work, body, leisure". A book of the same name was published in conjunction with the pavilion which discusses architecture in relation to these three issues and refers to technology employed in contemporary society, automation of cities and the relationship between the body and machines. According to one of the book editors and a curator of the Dutch Pavilion at the Biennale, Marina Otero Verzier:

By reflecting on this spectrum of spaces and theoretical viewpoints, Work, Body, Leisure seeks to offer visions that could be deployed in the reshaping of contemporary and future labor structures, and ultimately, our capacity to redesign them according to a different set of ethical principles (VERZIER, 2018, p. 70).

One of the book's chapters is entitled "Sex for sale", by historian and Amsterdam Museum curator Annemarie de Wildt (2018). In an essay containing abundant photographs, she presents a panorama of sex work in the Netherlands, with an emphasis on Amsterdam's Red Light District, the country's main representative of this activity. Based on an analysis of paintings and photographs, the author discusses the presence of sex workers in the country and points out changes to the architecture of the spaces in which they have worked over the years. The author also briefly mentions the implementation of Plan 1012 and puts forward a critique to the replacement of window prostitution with artists, designers, and the other services previously listed. What is important here is the inclusion of sex work as a prominent element in the Architecture Biennale, which is a kind of international showcase for the country. Regarding the windows characteristic of the Red Light

3 The growth in the number of rentals by the Airbnb platform has been subject of debate in Amsterdam, where availability of versus demand for accommodation is a delicate matter. 
Prostitution and the City's Image of Amsterdam

District, Marina Otero Verzier observed that:

Their modernist, rationally designed interiors dressed in white, regular tiles and equipped with fixed single beds, bidets, sinks, and the omnipresent locker, describe not only an efficient working space but also the transformation of a body into a worker (VERZIER, 2018, p. 67).

By presenting sex work - fairly and correctly - as a job, analysing changes to the architecture of working spaces, the narrative presented in the exhibition (based on an analysis of the book) suggests a divergence from the way this activity is viewed by the municipality of Amsterdam. If, on the one hand, we have seen countless efforts at local level to make it shrink into the urban fabric, losing its importance in the dynamics and image of the city, on the other hand, it is significant that sex work has been chosen, out of so many other work activities, to discuss the implications of architecture on the lives of workers and their relationship with technology. At least in terms of image and international marketing, this denotes yet another of the many contradictions and conflicts regarding sex work in distinct scales and contexts in the Netherlands.

\section{Conclusion}

Contrary to what we might imagine from what is widely published about sex work in Amsterdam, whose Red Light District is one of best known zones of sexual commerce in the world, this area continues to be disputed. Pena (2019a) has already demonstrated how the history of sex work in the city is marked by ruptures, discontinuities and confrontations, as well as important gains for sex workers. However, the implementation of Plan 1012 unveils a new chapter in the field of dispute that is the Red Light District. Authorized to work legally since 2000, a significant number of prostitution windows were closed between 2007 and 2018, as were other establishments characteristic of the area, such as sexshops and coffee shops. With the justification of combatting crime in the neighbourhood, the municipality embarked on a real crusade against the sex industry, by proposing deep alterations in the neighbourhood supported by the Plan 1012 .

If, on the one hand, there is an alleged need to combat criminality, on the other, the interest in cleaning up and promoting the gentrification of the area is evident. This opens up space for investment in higher quality products and services aimed at a wealthier public. The characteristic diversity of this area of the city was no longer aligned with the image that Amsterdam intended to project. However, despite interventions and improvements, and the replacement of many windows and coffee shops, the mass presence of fast food outlets suggests that the plan has perhaps not been so successful in attracting sophisticated restaurants to the area.

Within the current context, Plan 1012 reveals the municipality's ambition to become more competitive and attract domestic and international investment, while sex work has been viewed as an obstacle to its desired goals. Thus, the 
"urban renovation" of its most symbolic neighbourhood was used as a device to design and reposition it within the global market of cities. In addition to that, the city of Amsterdam's marketing activities have sought, on the one hand, to provide greater visibility to other city attractions and, on the other, to reduce the importance of sex work and the Red Light District in the widely disseminated image of the city. At national level, however, sex work was one of the themes addressed by the Netherlands in its Pavilion at the 16th Venice Architecture Biennale, providing evidence of differences in the way this issue is addressed in terms of the image of Amsterdam and of the Netherlands.

\section{Acknowledgements}

The research on which this article is based received funding from the National Council for Technological and Scientific Development (Conselho Nacional de Desenvolvimento Científico e Tecnológico: CNPQ) and the Coordination for the Improvement of Higher Education Personnel (Coordenação de Aperfeiçoamento de Pessoal de Nível Superior: CAPES). I would particularly like to thank Professor Dr Rachel Spronk for welcoming and supervising me between 2017 and 2018, when I was a Visiting $\mathrm{PhD}$ Fellow at the Amsterdam Institute for Social Science Research (AISSR) of the University of Amsterdam (UvA).

\section{Referências / References}

ADAMS, Cathy. I Amsterdam letters removed amid fears over mass tourism. The Independent, 06 de dezembro de 2018. Disponível em: $<$ https://www.independent.co.uk/travel/news-and-advice/amsterdam-lettersremoved-tourism-netherlands-rijksmuseum-a8669901.html $>$. Acesso em: 17 dez. 2018.

AALBERS, Manuel; DEINEMA, Michaël. Placing prostitution: The spatialsexual order of Amsterdam and its growth coalition. City, v. 16, n. 1-2, p. 129$145,2012$.

AALBERS, Manuel. Amsterdam. In: CHENG, Tsaiher (ed.). Red Light City. Montreal/Amsterdã: The Architecture Observer, 2016.

AMSTERDAM. Heart of Amsterdam: future perspectives 1012. Amsterdam: I amsterdam, 2008. Disponível em: $<$ https://www.amsterdam.nl/publish/pages/780659/heart_of_amsterdam.pdf $>$. Acesso em: 12 set. 2017.

AMSTERDAM. Amsterdam Marketing. Amsterdam Metropolitan Area: Visitors Survey 2016. Amsterdam: Amsterdam Marketing, 2016.

AMSTERDAM. Rekenkamer Metropool Amsterdam. Feitelijk verloop van Project 1012: Onderzoek Project 1012 - Tussentijdse rapportage. Amsterdã: RMA, $2018 . \quad$ Disponível em: 


\section{Prostitution and the City's Image of Amsterdam}

$<$ https://www.rekenkamer.amsterdam.nl/content/uploads/2018/01/Tussentijdse -rapportage-Feitelijk-verloop-Project-1012-1.pdf >. Acesso em: 10 dez. 2020.

CHENG, Tsaiher (ed.). Red Light City. Montreal : Amsterdã: The Architecture Observer, 2016.

DELEUZE, Gilles. Conversações, 1972-1990. São Paulo: Editora 34, 1992.

DE WILDT, Annemarie. Sex for sale. In: VERZIER, Mariana Otero; AXEL, Nick (eds.). Work, Body, Leisure. Rotterdam: Het Nieuwe Instituut, 2018.

HEKMA, Gert. How libertine is the Netherlands: exploring contemporary Dutch sexual cultures. In. BERNSTEIN, Elizabeth. Regulating sex: the politics of intimacy and identity. New York; London: Routledge, 2005.

JACQUES, Paola Berenstein. Espetacularização Urbana Contemporânea. Cadernos PPG-AU/FAUFBA, v. 2, p. 23-29, 2004.

KAVARATZIS, Mihalis; ASHWORTH, Gregory John. Partners in coffeeshops, canals and commerce: Marketing the city of Amsterdam. Cities, v. 24, n. 1, p. 16-25, 2007.

LEITE, Gabriela. (Entrevista) Daspu: Uma grife surpreendente. In: Caros Amigos, São Paulo, ano 9, n. 106, janeiro de 2006, p. 28-31.

LYNCH, Kevin. A imagem da cidade. 3. ed. São Paulo: Editora WMF Martins Fontes, 2011.

NIJMAN, Jan. Cultural globalization and the identity of place: the reconstruction of Amsterdam. Ecumene, v. 6, n. 2, 1999, p. 146-164. Disponível em: <https://www.jstor.org/stable/44252045?seq=1>. Acesso em: 25 jun. 2018.

OUTSHOORN, Joyce. Policy change in prostitution in the Netherlands: from legalization to strict control. Sexuality Research and Social Policy, v. 9, n. 3, p. 233-243, 2012.

PENA, João Soares. Além da vitrine: produção da cidade, controle e prostituição no Red Light District em Amsterdã. 2020. Tese (Doutorado Arquitetura e Urbanismo) - Faculdade de Arquitetura da Universidade Federal da Bahia.

PENA, João Soares. Gestão pública da prostituição no Brasil e na Holanda. Revista Políticas Públicas \& Cidades, v. 7, n. 1, p. 1-20, 2019a.

PENA, João Soares. Red Light City. Relações entre prostituição e urbanismo na cidade contemporânea. Resenhas Online, São Paulo, ano 18, n. 209.05, Vitruvius, 2019b. 
PHETERSON, Gail. The prostitution prism. Amsterdã: Amsterdam University Press, 1996.

VAINER, Carlos. Pátria, empresa e mercadoria: Notas sobre a estratégia discursiva do Planejamento Estratégico Urbano. In: ARANTES, Otília; VAINER, Carlos; MARICATO, Ermínia. A cidade do pensamento único: desmanchando consensos. 7. ed. Petrópolis: Vozes, 2012.

VERZIER, Marina Otero. Work, Body, LeisureI. In: VERZIER, Mariana Otero; AXEL, Nick (eds.). Work, Body, Leisure. Rotterdam: Het Nieuwe Instituut, 2018.

WONDERS, Nancy A.; MICHALOWSKI, Raymond. Bodies, Borders, and Sex Tourism in a Globalized World: A Tale of Two Cities- Amsterdamand Havana. Social Problems, v. 48, n. 4, p. 545-571, 2001.

ZUCKERWISE, Gail Meryl. Conceptualizing culture in discourses of policy and reform in Amsterdam. 2016. Tese (Doutorado) - University College London, Londres.

ZUKIN, Sharon. Paisagens urbanas pós-modernas: mapeando cultura e poder. Revista do Patrimônio Histórico e Artístico Nacional, n. 24, p. 205-219, 1996.

\section{Recebido em 31 de dezembro de 2020. Aceito em 10 de junho de 2021.}

Received in december 31, 2020. Accept in june 10, 2021. 